\title{
LA REVISTA COLOMBIANA DE OBSTETRICIA Y GINECOLOGÍA, UN PATRIMONIO INTRANSFERIBLE
}

\author{
Jesús Alberto Gómez Palacino*
}

\section{CRONOLOGÍA DE LOS DESACIERTOS}

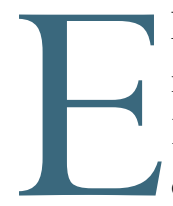

l 30 de marzo de 1943 los docentes e internos del pabellón de maternidad del Hospital de San Juan de Dios de Bogotá decidieron crear un ente orientado al desarrollo de la obstetricia en sus aspectos científicos y gremiales. La idea se concretó el 27 de mayo del mismo año con la fundación de la que se llamó Sociedad de Obstetricia de Colombia que obtuvo la Personería Jurídica mediante la Resolución 157 del Ministerio de Gobierno. Tiempo después -1947con la afiliación a la Sociedad de los ginecólogos que a la razón laboraban en el pabellón respectivo del mismo hospital, cambió su razón social por la de Sociedad Colombiana de Obstetricia y Ginecología, cuyo modelo se fue replicando en las capitales de los departamentos con su particular identificación -sociedades o asociaciones- que con el paso de los años a instancias y la definitiva participación de la Sociedad de Bogotá, se congregaron bajo la denominación de FECOLSOG, sigla de la Federación Colombiana de Sociedades de Obstetricia y Ginecología, cuya oficialización se llevó a cabo el 4 de diciembre de 1967 en la ciudad de Cúcuta con ocasión del VII Congreso Colombiano de la especialidad. Obtuvo la Personería Jurídica No. 2624, el 6 de agosto de 1968.

Expresidente de la Sociedad Colombiana de Obstetricia y Ginecología, 196566. Expresidente de FECOLSOG, 1971-73. Exdirector de la REVISTA COLOMBIANA DE OBSTETRICIA Y GINECOLOGÍA, 1960-61. Director actual de la Revista Controversias en Ginecología y Obstetricia.
No es la oportunidad ni el espacio para registrar lo que después de más de 60 años ha significado para la ginecología y la obstetricia nacionales y sus cultores, la magna tarea, la dimensión y la influencia de la primigenia Sociedad Colombiana de Obstetricia y Ginecología, surgida de los visionarios que en un viejo pabellón del centenario Hospital de San Juan de Dios dieron origen a una bella empresa inspirada en los más profundos anhelos de superación colectiva y que por inexplicables razones permitió que la Federación por ella propiciada asumiera su nombre, tal como ocurrió en la asamblea general celebrada en 1996 en la ciudad de Medellín. Afortunadamente, el 11 de abril de 2003 en la asamblea general reunida en Cartagena para reformar sus estatutos la organización retomó su nombre de FECOLSOG, con lo cual se reparó el desacierto previamente cometido. Así expiró la SCOG.

Fundada por la primigenia Sociedad Colombiana de Obstetricia y Ginecología y como su órgano oficial, hizo su aparición en 1950 la REVISTA COLOMBIANA DE OBSTETRICIA Y GINECOLOGÍA, avalada en su momento por el Ministerio de Gobierno según Resolución 218. Con más de medio siglo de circulación ininterrumpida ha sido el vehículo de difusión científica de la especialidad más importante del país. A través de 55 volúmenes se han dado a conocer las investigaciones y trabajos científicos llevados a cabo por médicos colombianos de todo el país. Algunos han merecido su reproducción en medios extranjeros, otros conocidos a través de referencias bibliográficas e intercambio 
con publicaciones foráneas. Muchos presentados en congresos, simposios y eventos de distinta naturaleza han enriquecido la literatura médica nacional por intermedio de sus memorias. Han sido los directores de la Revista quienes a través de los años, sorteando muchas dificultades y sin retribución diferente a la satisfacción personal por el cumplimiento del compromiso adquirido, han hecho de su desempeño una causa.

A partir del año 1968, a poco de fundada la Federación, la Revista asumió la representación tanto de ASBOG como de FECOLSOG. Ha sido su espíritu el de mutua colaboración sin que medie compromiso alguno de los que se protocolizan jurídicamente en circunstancias contractuales. El 15 de octubre de 1999 las directivas, tanto de la Asociación Bogotana como de la Sociedad Colombiana de Obstetricia y Ginecología, firmaron el Convenio que alguien llamó "pacto de caballeros" que a la letra reza:

"Entre la Sociedad Colombiana de Obstetricia y Ginecología -S.C.O.G. representada legalmente por su Presidente Dr. GUIDO PARRA ANAYA, con domicilio principal en esta ciudad de Santafé de Bogotá, constituida conforme lo establece la legislación comercial colombiana vigente y la Asociación Bogotana de Obstetricia y Ginecología -A.S.B.O.G., igualmente sociedad debidamente constituida, representada legalmente por la Dra. MARÍA TERESA PERALTA ABELLO, hemos celebrado el presente CONVENIO de DISTRIBUCIÓN DE GASTOS, COSTOS, INGRESOS Y REPRESENTACIÓN de la REVISTA DE OBSTETRICIA Y GINECOLOGÍA, órgano de difusión de la especialidad médica y en circulación desde hace más de cincuenta años.

\section{CONSIDERACIONES}

1. Las mencionadas entidades son propietarios de la Revista de Obstetricia y Ginecología.

2. De manera paritaria, la dirección tanto científica como administrativa de la Revista de Obstetricia y Ginecología ha estado a cargo de las dos entidades ya mencionadas.
3. La Revista de Obstetricia y Ginecología fue fundada y creada por la ASOCIACIÓN BOGOTANA DE OBSTETRICIA Y GINECOLOGÍA, llamada anteriormente Sociedad Colombiana de Obstetricia y Ginecología en Diciembre de 1949.

4. La ASOCIACIÓN BOGOTANA DE OBSTETRICIA Y GINECOLOGÍA, llamada antes Sociedad Colombiana de Obstetricia y Ginecología donó el cincuenta por ciento (50\%) de la misma a la actual Sociedad Colombiana de Obstetricia y Ginecología -S.C.O.G. anteriormente denominada FEDERACIÓN COLOMBIANA DE SOCIEDADES de OBSTETRICIA Y GINECOLOGÍA -FECOLSOG-.

5. La revista de Obstetricia y Ginecología cuenta con manejo administrativo y científico compartido por las entidades que suscriben el presente convenio y se rige por los estatutos de cada una de ellas.

\section{CONVENIO}

1. Las partes integrantes de este CONVENIO acuerdan ratificar por el mismo que la Revista de Obstetricia y Ginecología es de propiedad de la Sociedad Colombiana de Obstetricia y Ginecología -S.C.O.G. y de la Asociación Bogotana de Obstetricia y Ginecología -A.S.B.O.G. en partes iguales, esto es, cada una de las entidades cuenta con el cincuenta por ciento de la Revista.

2. La Dirección Científica y Administrativa de la Revista está a cargo de las entidades que celebran este convenio quienes nombran sus respectivos directores de manera autónoma e independiente para los periodos que acuerden entre sí y acordes con lo establecido en sus respectivos estatutos.

3. Las partes acuerdan que el manejo, control, autorizaciones y recibo de soportes sobre ingresos y gastos de la Revista de Obstetricia y Ginecología estará a cargo tanto del Director Administrativo como del Director Científico y en consecuencia, la celebración de contratos, pagos, ingresos, apertura y manejo de cuentas bancarias, contribuciones y tasas y cualquier otro 
acto que celebre la Revista, será de exclusiva y directa responsabilidad compartida por parte de las Entidades directoras.

4. Todo el manejo y control contable de la Revista estará a cargo de sus Direcciones Administrativa y Científica, requeriéndose la suscripción conjunta de contratos, acuerdos, autorización de gastos, autorizaciones de pagos, giro de cheques o cualesquiera otros títulos valores y aprobación de los estados de cuentas y balances de las mismas.

5. Las cuentas bancarias, los inventarios de equipos, la adquisición de bienes muebles o inmuebles se harán a nombre de las mencionadas Entidades.

6. Se delega en los Representantes Legales de las Entidades intervinientes en este CONVENIO para que procedan en los trámites y gestiones necesarias para dar cabal cumplimiento al alcance de lo aquí consignado".

No obstante el documento transcrito, episódicamente en diferentes eventos y circunstancias, la Revista ha sido víctima de apetencias y no pocas veces de desobligantes epítetos de quienes poco han aportado científicamente a su prestigio y se toman la vocería de FECOLSOG, entidad que por lo demás de manera sucesiva ha pretendido modificar su participación en la Revista, propuesta considerada no viable por parte de ASBOG por razones que quedaron consignadas en algunos párrafos de la comunicación cursada el 26 de febrero del presente año con la firma del Presidente de la Asociación y con destino a la Presidencia de la Sociedad Colombiana:

"Con nuestro respetuoso saludo nos permitimos solicitar a usted un pronunciamiento definitivo de SCOG respecto de su participación en la Revista Colombiana de Obstetricia y Ginecología.

Tal como así le manifestamos en comunicación de mayo del anterior año, la propuesta de adelantar una negociación sobre el particular no tuvo ninguna acogida en el seno de la Asociación.

Sea esta la oportunidad para manifestar el afán de la Asociación sobre la participación futura de la
Sociedad en este asunto, no sin antes dar a conocer algunas razones sobre las cuales el pronunciamiento de ASBOG es inapelable:

- El origen de la Revista, su desarrollo y divulgación, su edición sin interrupción por 54 años estableciéndose como la revista médica más antigua de Colombia, constituyen un valioso patrimonio científico de ASBOG, no cuantificable frente a opciones de negociación. Quiere ello decir que dentro del proceso de acuerdo para continuar en el manejo y divulgación de la Revista, no es tema de discusión una eventual negociación en la cual ASBOG se desprenda de su participación en la mencionada Revista.

- Como no escapa al conocimiento de las Entidades vinculadas a este asunto, la participación de la Sociedad Colombiana de Obstetricia y Ginecología nace de la especial y voluntaria invitación que formulara ASBOG, por ese entonces bajo la denominación de SCOG y conforme al pacto de compromiso asumido, la Dirección de la Revista ha comportado valiosas satisfacciones en cuanto a su crecimiento, importancia y reconocimiento a nivel nacional. En ese orden de ideas la invitación formulada hace ya 36 años se mantiene vigente bajo las mismas condiciones actuales y corresponde a la Sociedad decidir su participación y aporte.

- Planteada la posición de ASBOG en los puntos anteriores y en el evento, que lamentamos de antemano, que de no seguir contando con su participación, los perjuicios que se causarían a la Revista constituyen una afrenta al esfuerzo y dedicación con los cuales se ha mantenido su importancia durante toda su historia. Por lo expuesto, reiteramos nuestro interés de mantener la Revista con la dirección, manejo y posicionamiento dentro del cuerpo médico, planteando incluso, la opción de legalización de sus componentes directivas para afianzar el espíritu que dio lugar a su participación en la misma desde enero de 1968.

En virtud de lo expuesto, que solamente refleja en mínima proporción el derecho primario e inobje- 
table de ASBOG respecto de la Revista, nuevamente reafirmamos nuestra cordial invitación para conocer su parecer sobre el particular y a la espera de una favorable decisión que permita seguir contando con su valioso aporte al éxito de la Revista Colombiana de Obstetricia y Ginecología. En caso contrario, no sólo lamentamos su respuesta, sino que ello nos obligará a precaver todo lo necesario para cesar su participación”.

Hasta aquí el documento.

Por todo lo anterior -y mucho más- la REVISTA COLOMBIANA DE OBSTETRICIA Y
GINECOLOGÍA, que recientemente ha recibido el respaldo del sistema de Homologación e Indexación de Revistas Científicas y Tecnológicas de COLCIENCIAS, gracias a la gestión de sus directores, y está a la espera de la respuesta de los sistemas internacionales, no podrá ser enajenada.

Deseo, además, agregar mi invocación para que las directivas recientemente nombradas devuelvan a FECOLSOG la majestad consagrada desde sus inicios en la Villa del Rosario en Cúcuta el 4 de diciembre de 1967. Que la cordura reemplace la intemperancia y sus asambleas vuelvan a ser el escenario de la inteligencia y la controversia positiva, características de un pasado memorable. 